Supporting Information

\title{
Design of Potential Pharmaceutical-Based Metal Complexes Derived from Cromolyn a Mast Cell Stabilizer
}

\author{
Israel Rodriguez ${ }^{\dagger}, \|$, Jeaninna Flores Bello ${ }^{\xi, t}, \|$, Joyce Marie Serrano Valcárcel ${ }^{\dagger, t}$, and \\ Vilmali López-Mejías ${ }^{\dagger+t, * *}$ \\ †Department of Chemistry, University of Puerto Rico, Río Piedras \\ San Juan, Puerto Rico, 00931 United States \\ ${ }^{\S}$ Department of Mathematics, University of Puerto Rico, Río Piedras \\ San Juan, Puerto Rico, 00931 United States \\ ${ }^{*}$ Crystallization Design Institute, Molecular Sciences Research Center, \\ University of Puerto Rico, San Juan, Puerto Rico, 00926 United States
}

"These authors contributed equally

*vilmali.lopez@upr.edu 


\section{Table of Contents}

I. Experimental $\quad$ S3

II. Optical Micrographs $\quad$ S3

III. Polarized Optical Micrographs $\quad$ S4

IV. Raman Spectroscopy S5

$\begin{array}{ll}\text { V. Micro-powder X-ray Diffraction } & \text { S7 }\end{array}$

VI. Single Crystal X-ray Diffraction $\quad$ S9

VII. Thermogravimetric Analysis $\quad$ S14

VIII. Scanning Electron Microscope Coupled/Energy Dispersion Spectroscopy S16

$\begin{array}{ll}\text { IX. Dissolution Profiles } & \text { S20 }\end{array}$

$\begin{array}{lll}\text { X. References } & \text { S23 }\end{array}$ 


\section{Experimental}

\subsection{Materials.}

Calcium nitrate tetrahydrate $\left[\mathrm{Ca}\left(\mathrm{NO}_{3}\right)_{2} \cdot 4 \mathrm{H}_{2} \mathrm{O}, 99 \%\right.$ pure $]$, zinc nitrate hexahydrate $\left[\mathrm{Zn}\left(\mathrm{NO}_{3}\right)_{2} \cdot 6 \mathrm{H}_{2} \mathrm{O}, 98 \%\right.$ pure], magnesium nitrate hexahydrate $\left[\mathrm{Mg}\left(\mathrm{NO}_{3}\right)_{2} \cdot 6 \mathrm{H}_{2} \mathrm{O}, 99 \%\right.$ pure] and cromolyn sodium $\left(\mathrm{CS}, 95 \%\right.$ pure), hydrochloric acid $(\mathrm{HCl}, 37 \%)$, ethyl alcohol $\left[\mathrm{CH}_{3} \mathrm{CH}_{2} \mathrm{OH}\right.$, 200 proof], phosphate buffer saline (PBS) tablets were purchased from Sigma-Aldrich (St. Louis, MO). Stock solutions of HCl (USP grade, 0.01-0.05 M) were used for pH adjustments. Nanopurified water $(18.23 \mathrm{MOhm} / \mathrm{cm})$ was utilized as obtained from a water purification system Aries Filter (Gemini) in the preparation of solvents, dissolution profiles, and synthesis. All materials were used "as received" without further purification. Figure S1 depicts the molecular structure of cromolyn, the ligand utilized within this work.<smiles>O=C(O)c1cc(=O)c2c(OCC(O)COc3cccc4c3C(=O)CC(C(=O)O)O4)cccc2o1</smiles>

Figure S1. Molecular structure of cromolyn.

\section{Optical micrographs}

The concentration used of CS for the synthesis of the metal-complexes in both water and 1:1 water:ethanol mixtures are below $(10.00 \mathrm{mg} / \mathrm{mL})$ which is noted by several authors as the critical self-association concentration, thus a monomeric species predominates under these conditions. ${ }^{1-3}$

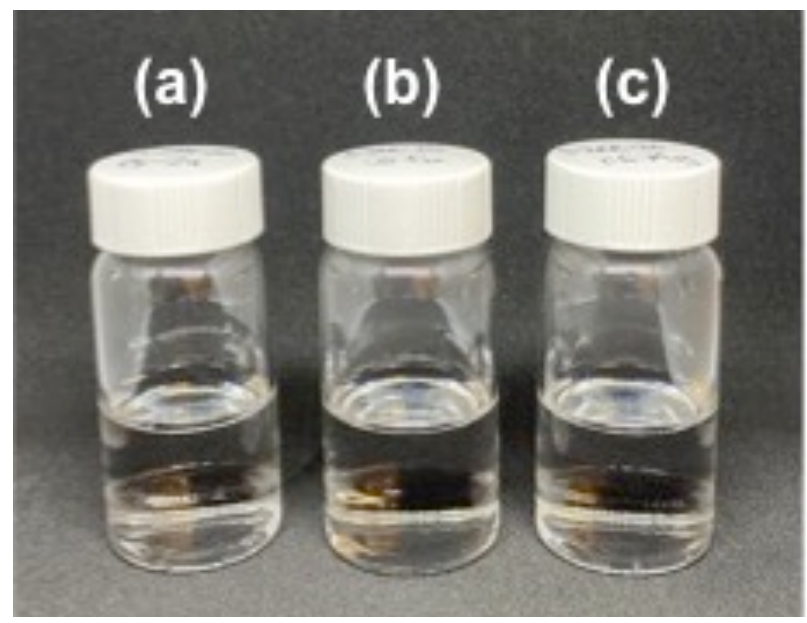

Figure S2. Optical micrographs for the different CS solutions for each synthesis before the addition of the corresponding metal salt (a) $\mathrm{Zn}\left(\mathrm{NO}_{3}\right)_{2}: \mathrm{CS}\left(1.65 \mathrm{mg} / \mathrm{mL}\right.$, water), (b) $\mathrm{Ca}\left(\mathrm{NO}_{3}\right)_{2}: \mathrm{CS}$ (2.56 mg/mL, 1:1 water:ethanol), and (c) $\mathrm{Mg}\left(\mathrm{NO}_{3}\right)_{2}: \mathrm{CS}(2.56 \mathrm{mg} / \mathrm{mL}, 1: 1$ water:ethanol). 


\section{Polarized optical micrographs}

Three novel pharmaceutical metal complexes (pMCs), Cromolyn-Zn, Cromolyn-Mg, and Cromolyn-Ca were formed through reactions under controlled temperature and $\mathrm{pH}$ conditions. The single crystals of the resulting pMCs were observed in a Nikon Eclipse LV100NPOL. The reaction products observed in the case of Cromolyn-Zn and Cromolyn-Ca appeared as needlelike crystals whereas those obtained for Cromolyn-Mg presented a block-like morphology. The polarized optical micrographs displayed on Figure S3 were processed using the NIS-Elements BR 4.30.01 software.

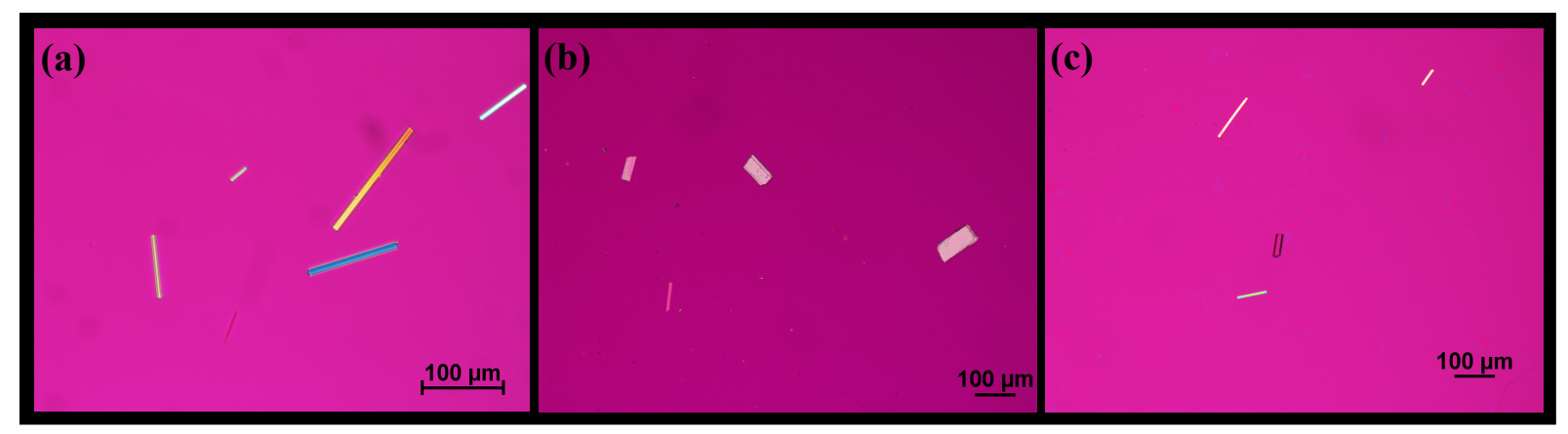

Figure S3. Polarized optical micrographs of three pharmaceutical metal complexes (pMCs) depicting single crystals of (a) Cromolyn-Zn, (b) Cromolyn-Mg, and (c) Cromolyn-Ca for the Cromolyn-based metal complexes. 


\section{Raman Vibrational Spectroscopy}

Raman spectra were recorded at room temperature. Figures S4.1-S4.3 depict the overlay of the experimental Raman spectra of the three Cromolyn-based metal complexes and CS, respectively.

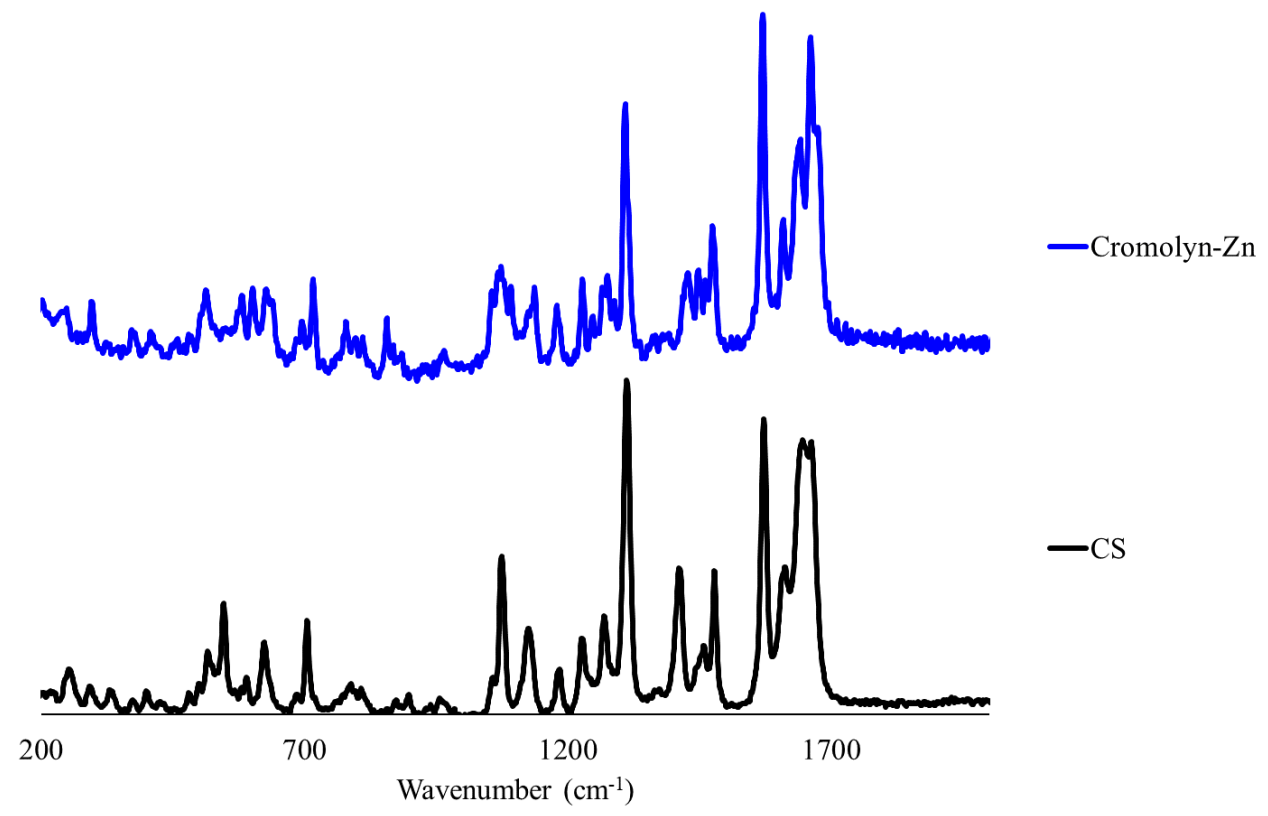

Figure S4.1. Raman spectra overlay of "as received" CS (bottom, black), and the synthesized Cromolyn-Zn (top, blue). 


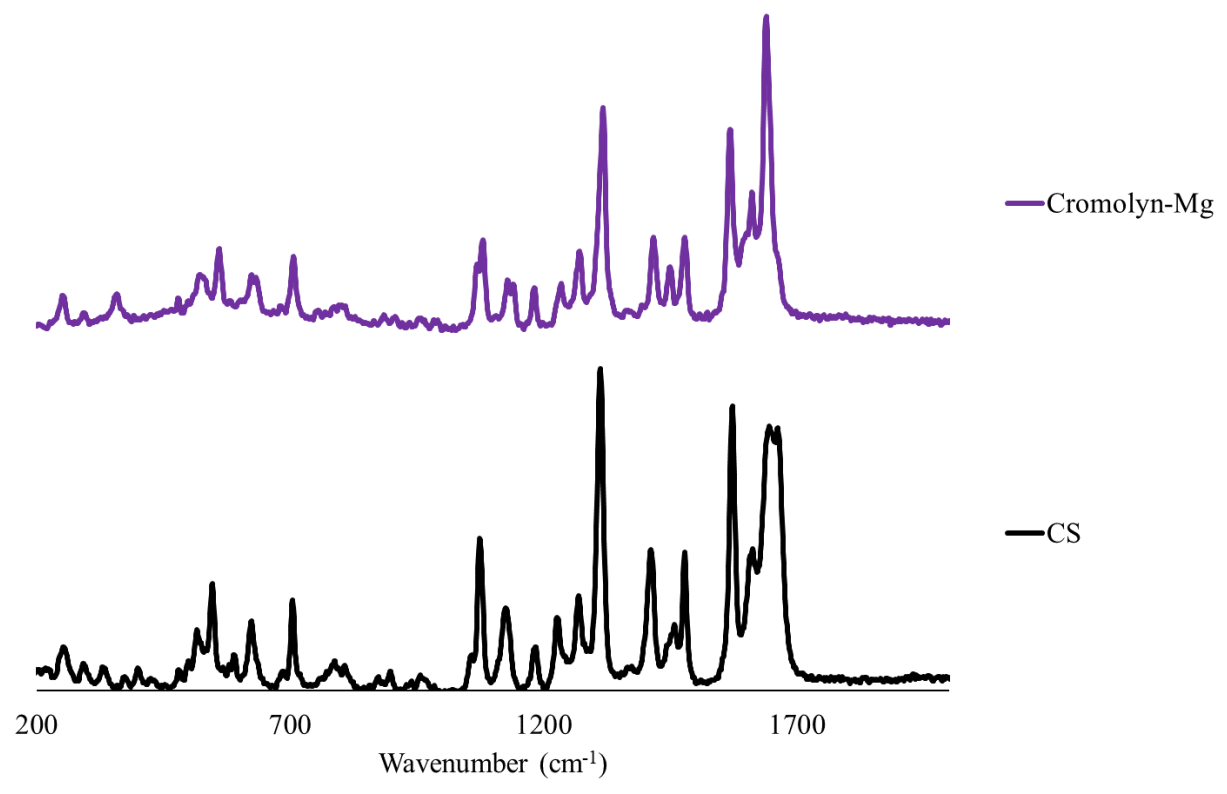

Figure S4.2. Raman spectra overlay of "as received" CS (bottom, black), and the synthesized Cromolyn-Mg (top, purple).

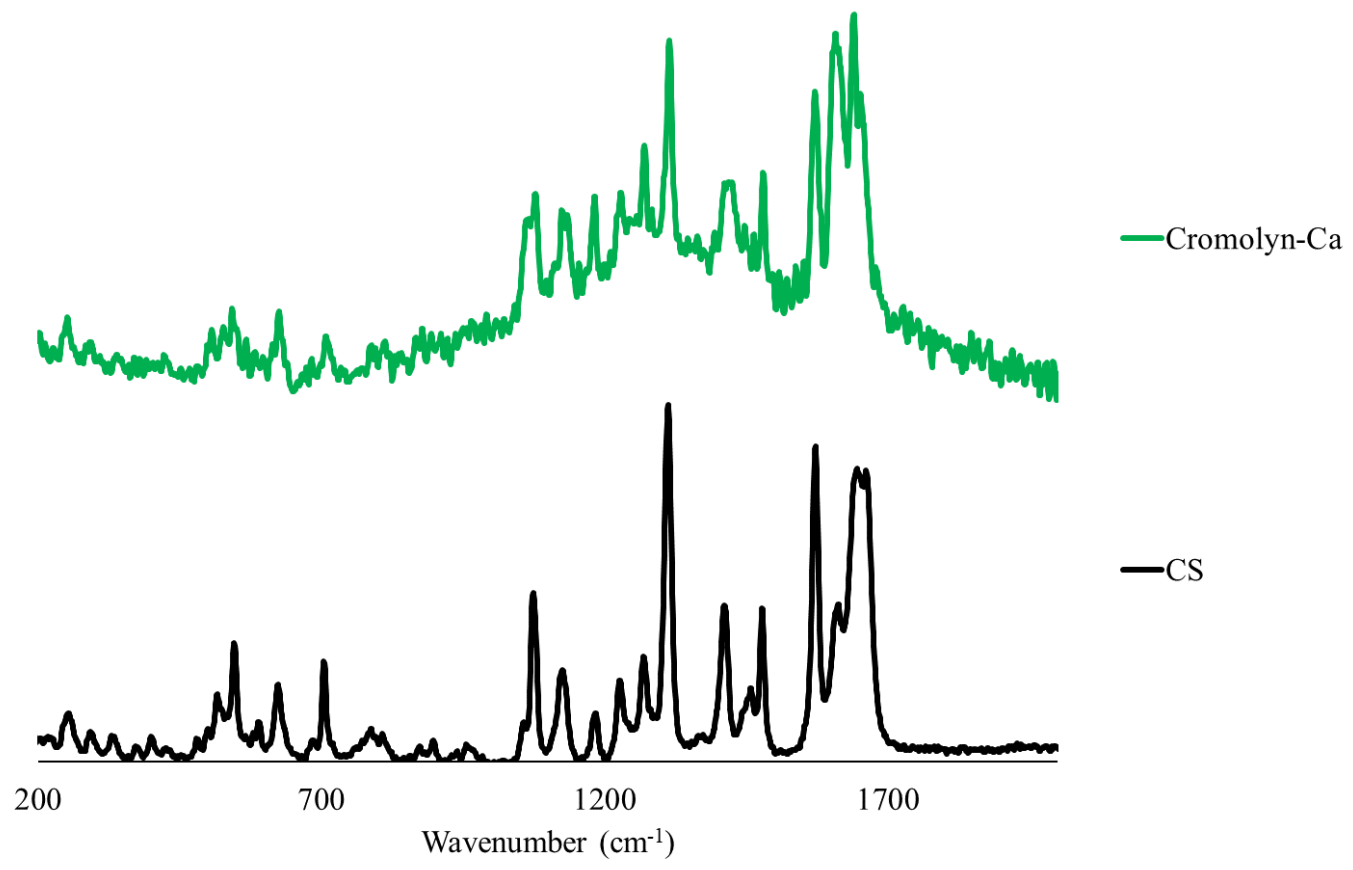

Figure S4.3. Raman spectra overlay of "as received" CS (bottom, black), and the synthesized Cromolyn-Ca (top, green). 


\section{Micro-powder X-ray Diffraction (PXRD)}

Figures S5.1-S5.3 illustrate the overlay of the experimental powder X-ray diffraction pattern of CS compared to the each of the pMCs.

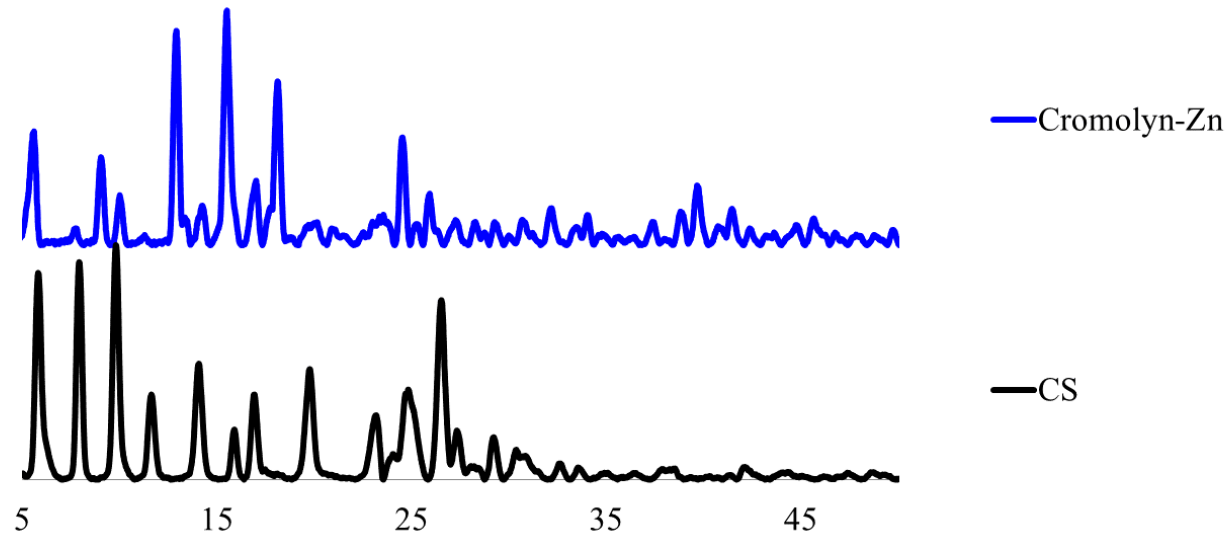

$2 \theta\left({ }^{\circ}\right)$

Figure S5.1. Powder X-ray diffractogram overlay of "as received" CS (bottom, black) and synthetized Cromolyn-Zn (top, blue).

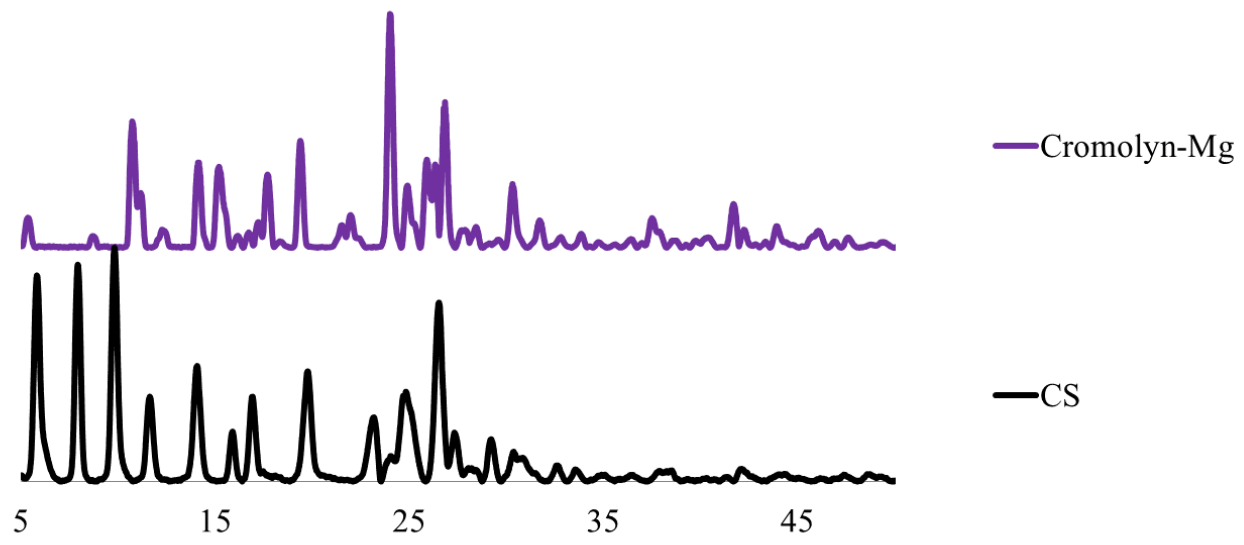

$2 \theta\left({ }^{\circ}\right)$

Figure S5.2. Powder X-ray diffractogram overlay of "as received" CS (bottom, black) and synthetized Cromolyn-Mg (top, purple). 


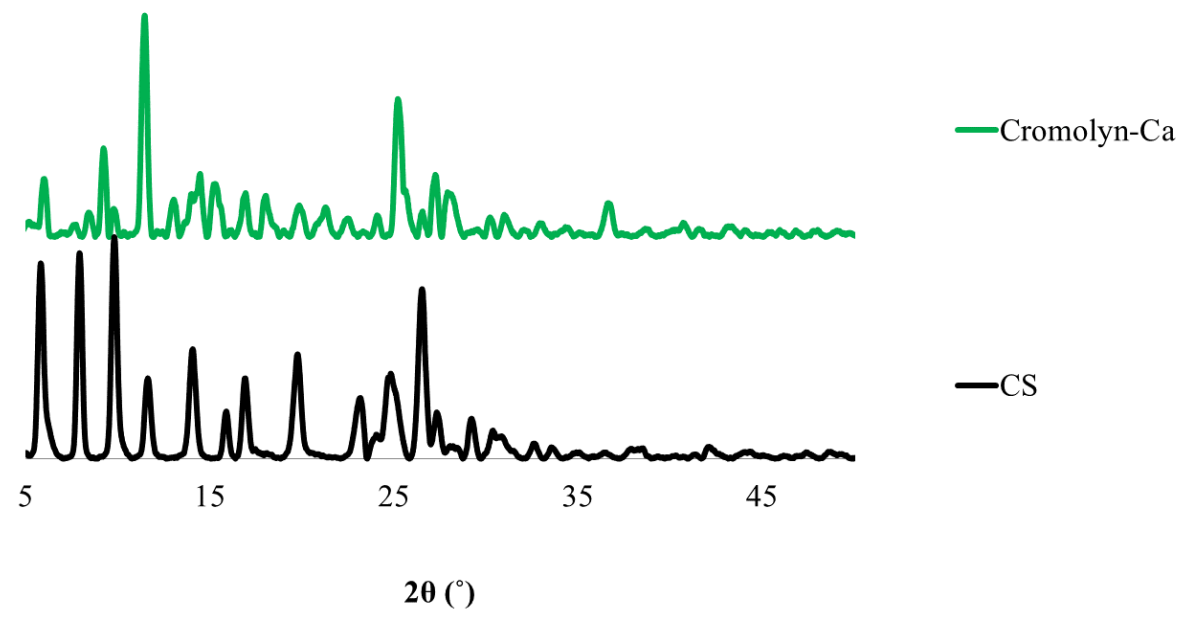

Figure S5.3. Powder X-ray diffractogram overlay of "as received" CS (bottom, black) and synthetized Cromolyn-Ca (top, green). 


\section{Single Crystal X-ray Diffraction (SCXRD)}

Figures S6.1, S6.3, and S6.5 illustrate the molecular structure, and asymmetric unit of Cromolyn-based pMCs. Figures S6.2, S6.4, and S6.6 presents the ORTEPs for the refined structures of the Cromolyn-based pMCs. Figures S6.7-S6.9 portray overlay of the simulated and experimental powder patterns for the structures solved within this study.

\section{Cromolyn-Zn}

(a)

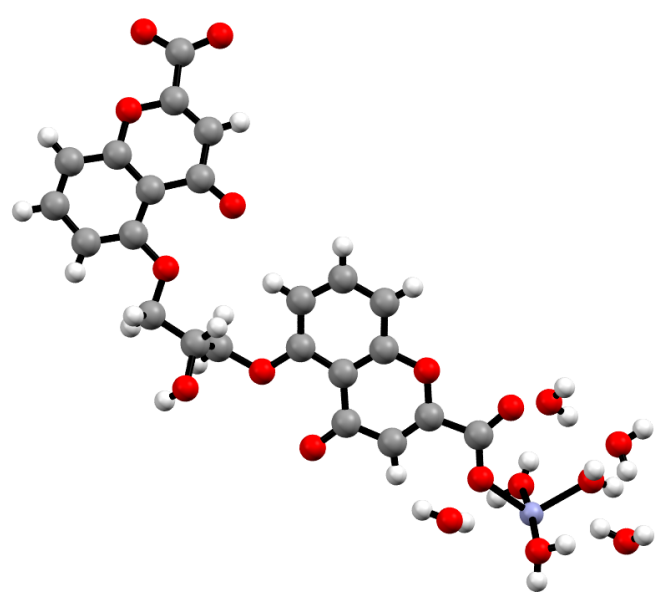

(b)

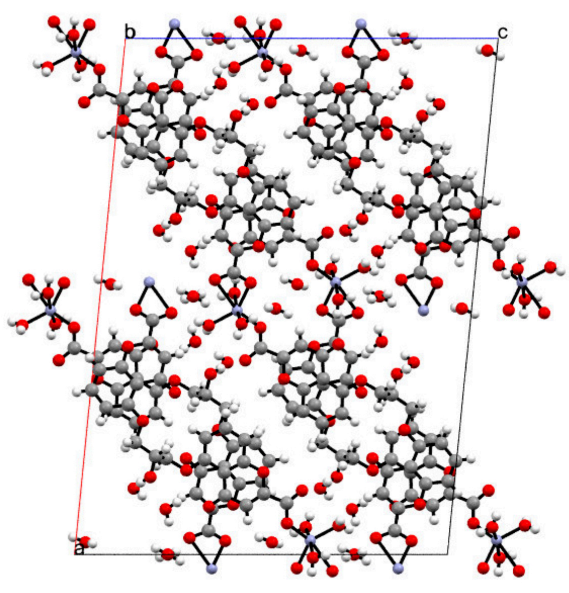

Figure S6.1. Molecular structure of (a) the asymmetric unit, and (b) crystalline packing of Cromolyn-Zn along $b$-axis.

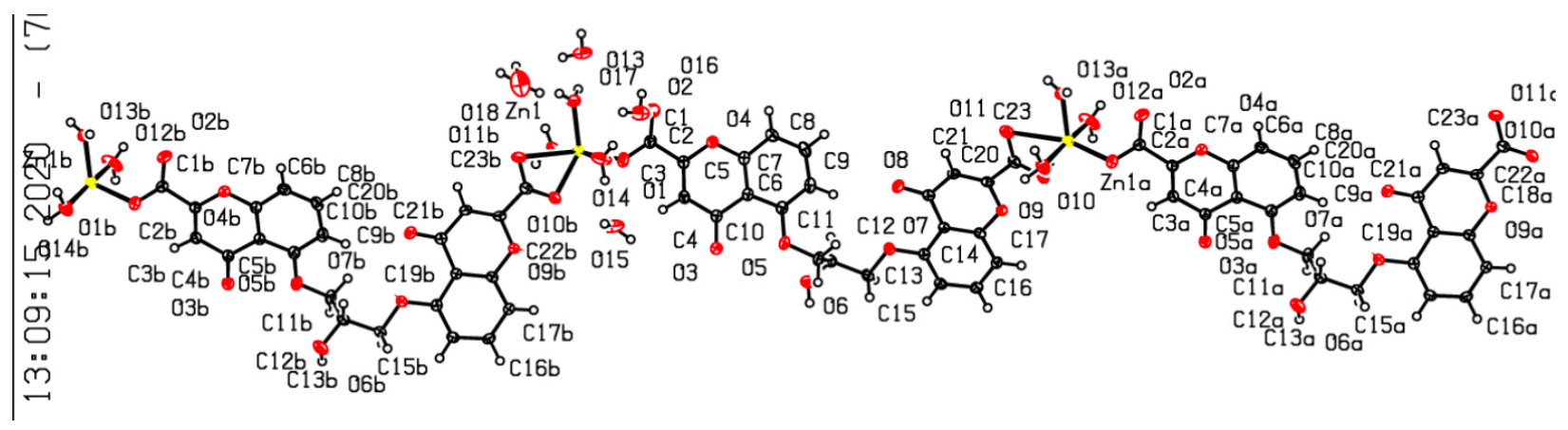

Figure S6.2. ORTEP (atoms labeled) representation of Cromolyn-Zn. 
(a)

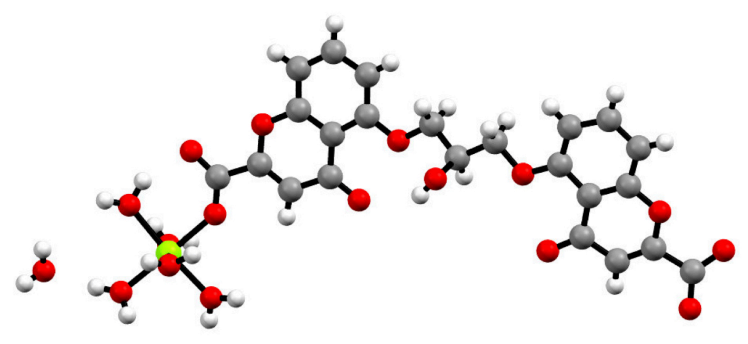

(b)

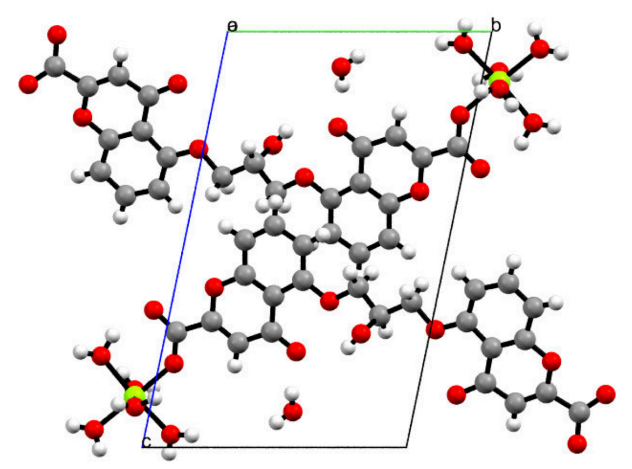

Figure S6.3. Molecular structure of (a) the asymmetric unit, and (b) crystalline packing of Cromolyn-Mg along $a$-axis.

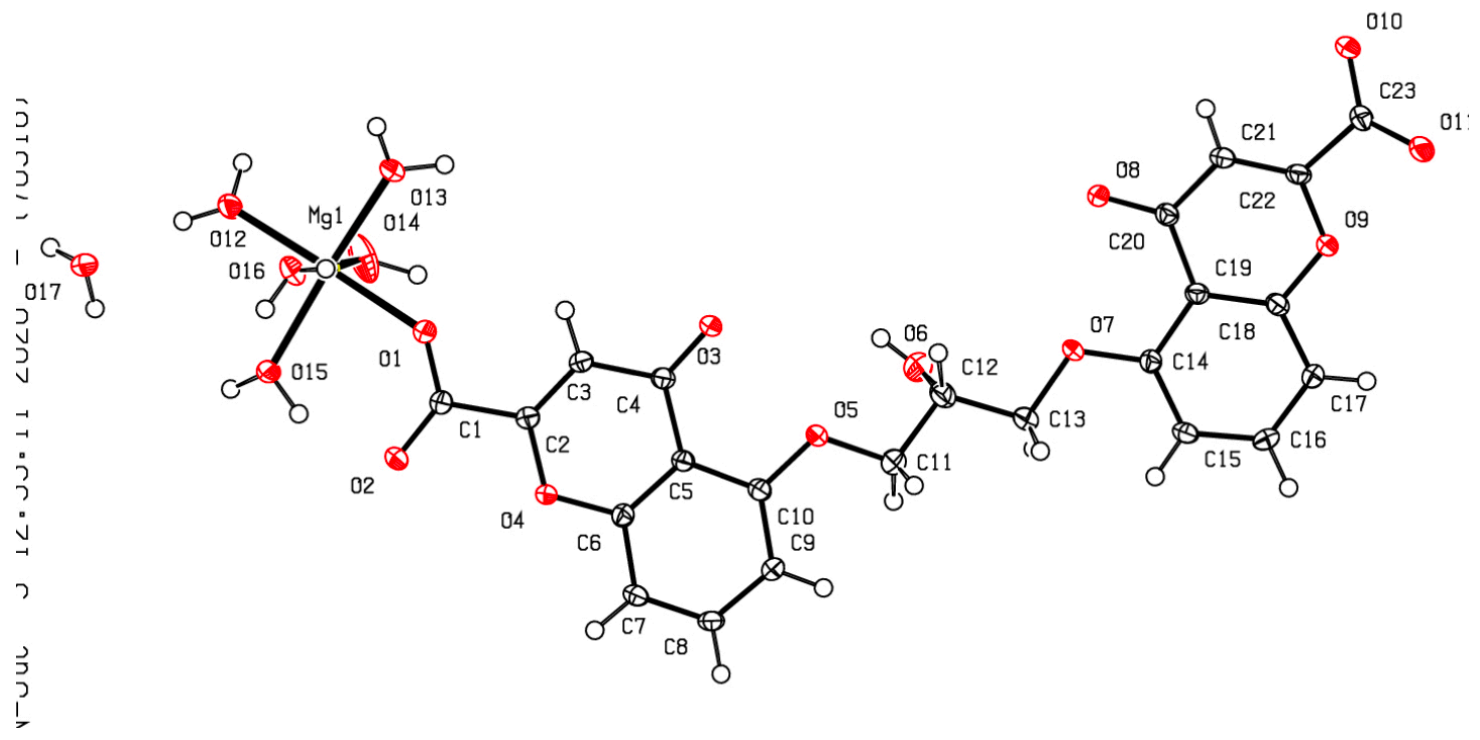

Figure S6.4. ORTEP (atoms labeled) representation of Cromolyn-Mg. 


\section{Cromolyn-Ca}

(a)

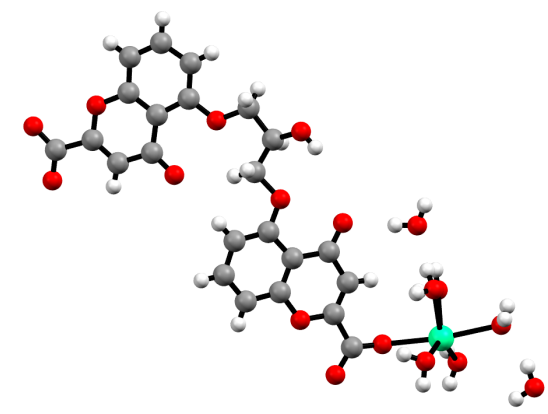

(b)

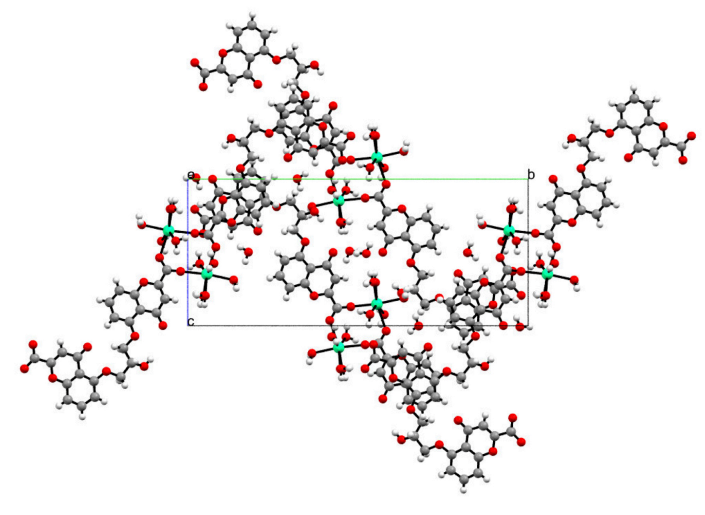

Figure S6.5. Molecular structure of (a) the asymmetric unit, and (b) crystalline packing of Cromolyn-Ca along $a$-axis.

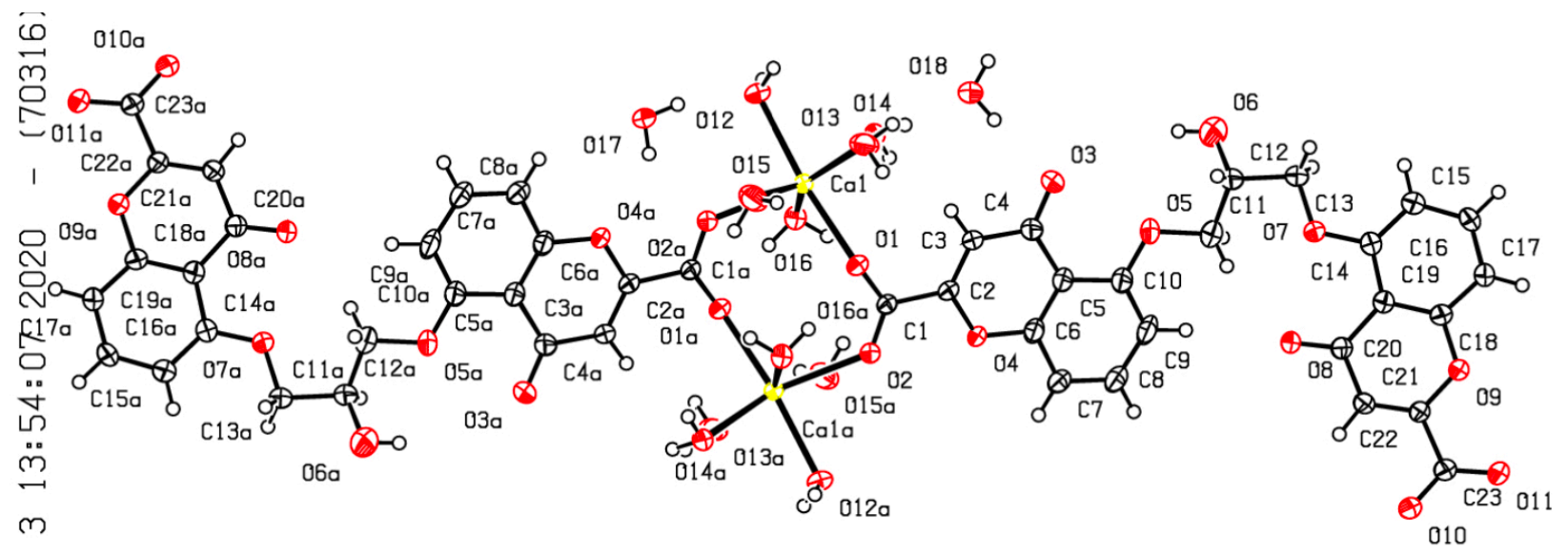

Figure S6.6. ORTEP (atoms labeled) representation of Cromolyn-Ca. 


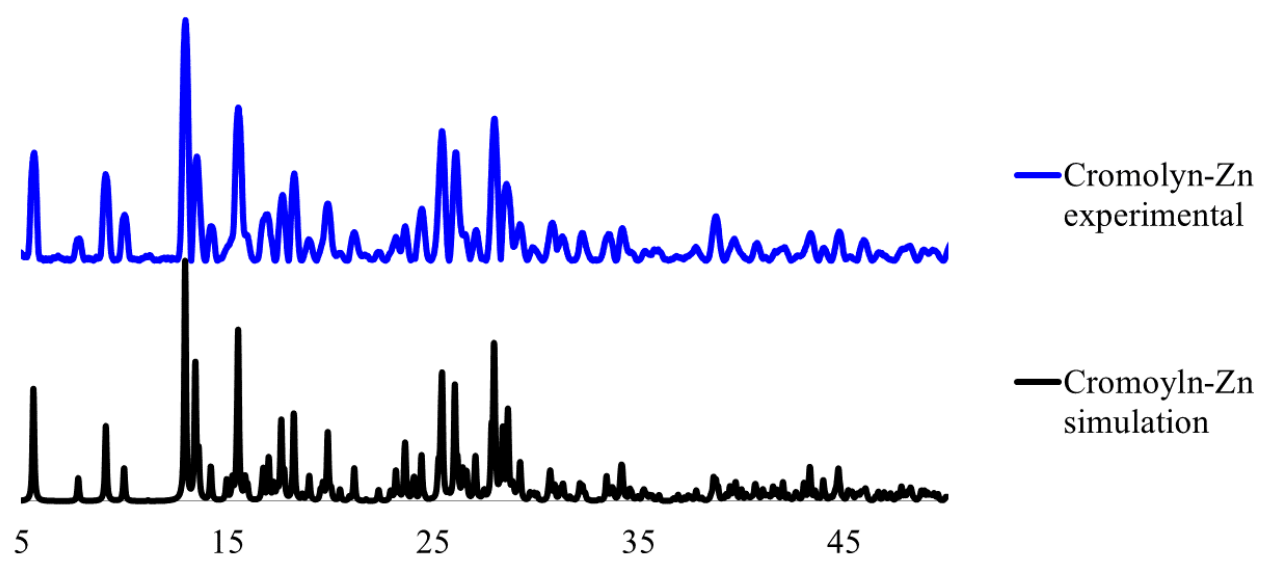

$2 \theta\left({ }^{\circ}\right)$

Figure S6.7. Simulated (bottom, black) and experimental (top, blue) powder X-ray diffraction pattern overlay of Cromolyn-Zn carried out at $100 \mathrm{~K}$.

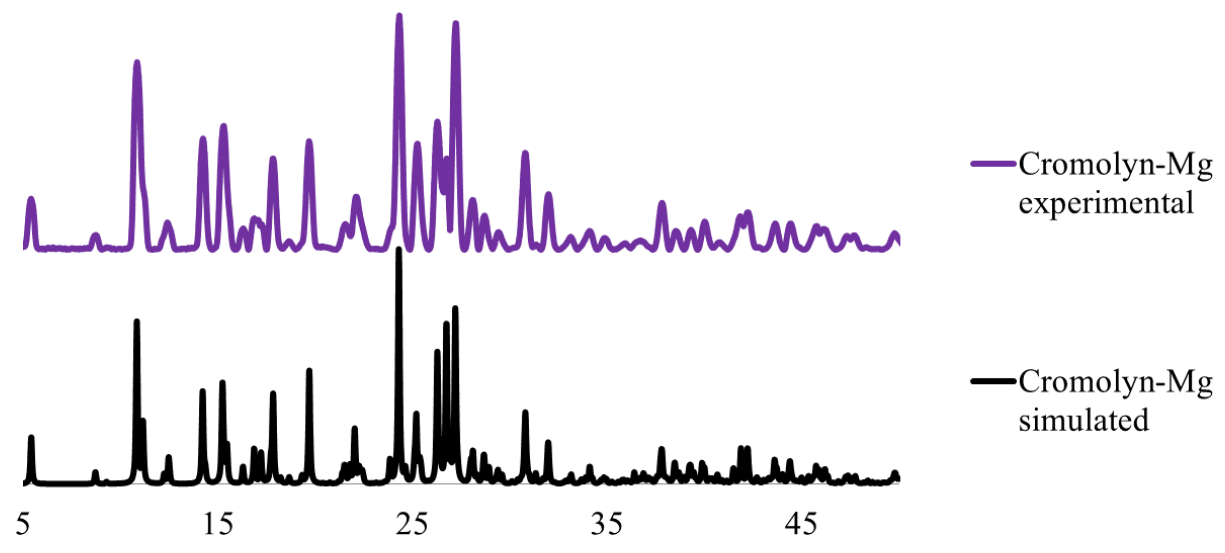

$2 \theta\left({ }^{\circ}\right)$

Figure S6.8. Simulated (bottom, black) and experimental (top, purple) powder X-ray diffraction pattern overlay of Cromolyn-Mg carried out at $100 \mathrm{~K}$. 


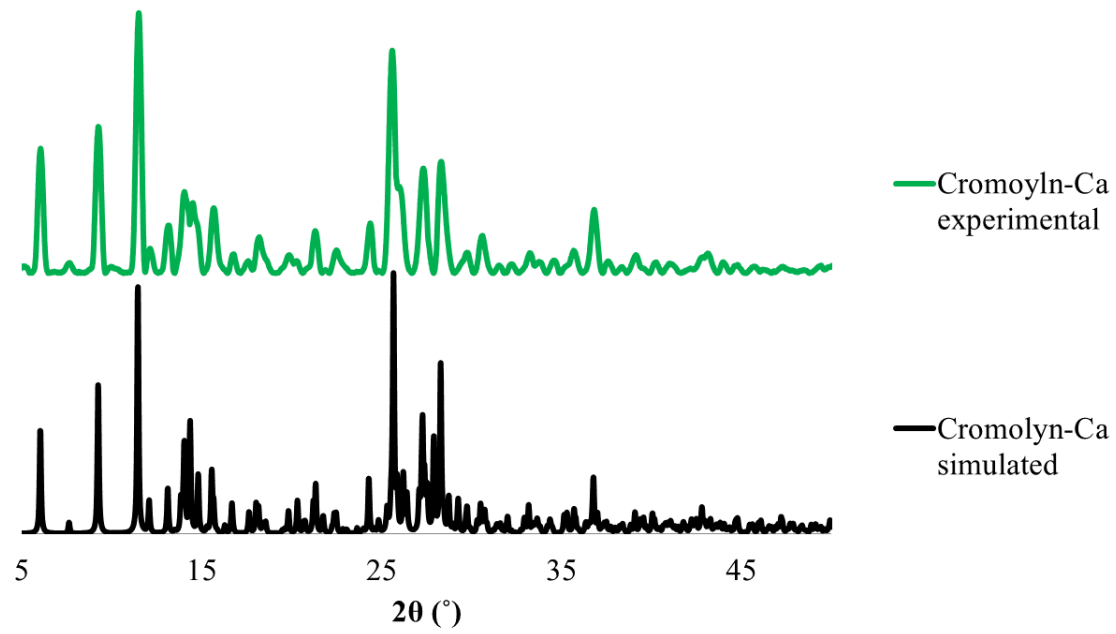

Figure S6.9. Simulated (bottom, black) and experimental (top, green) powder X-ray diffraction pattern overlay of Cromolyn-Ca carried out at $100 \mathrm{~K}$. 


\section{Thermogravimetric Analysis}

Figures S7.1-S7.3 depict the overlay of the TGA thermographs for Cromolyn-Zn, Cromolyn-Mg, Cromolyn-Ca, respectively with CS.

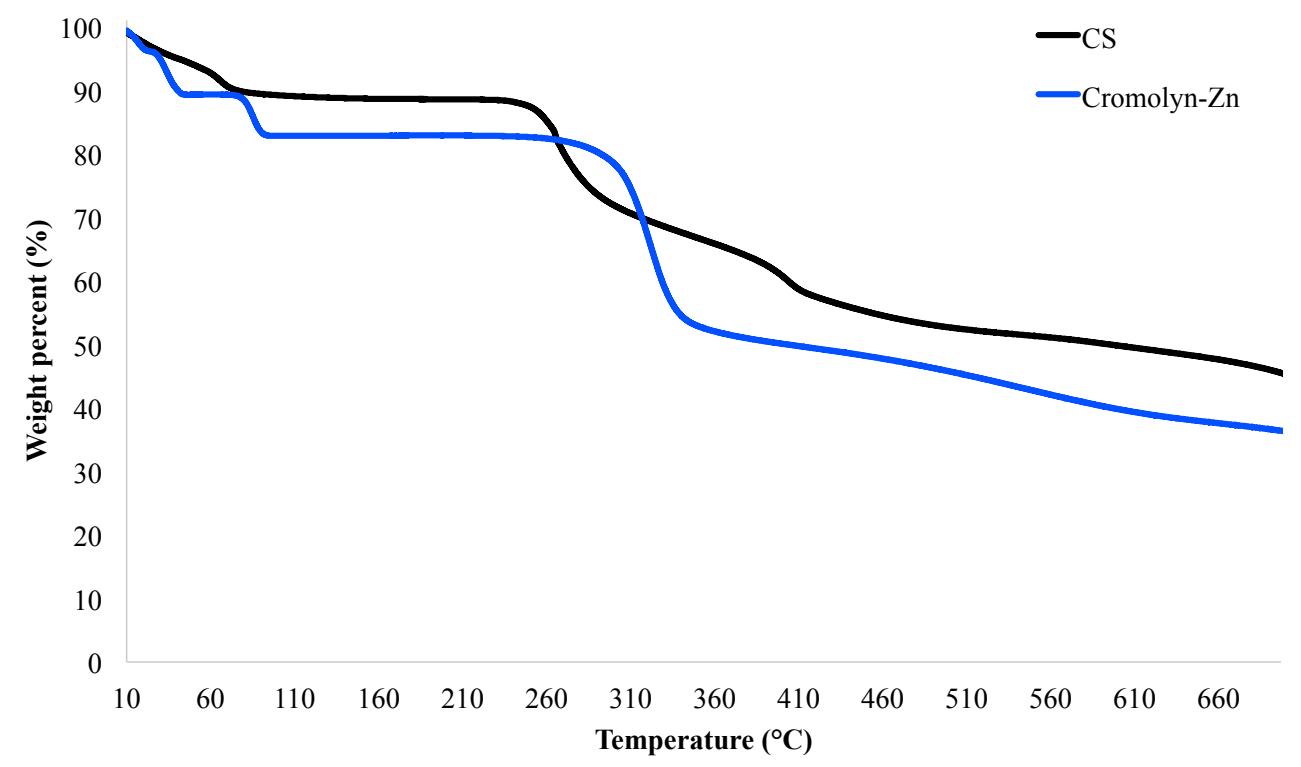

Figure S7.1. The TGA thermograph of Cromolyn-Zn starts with a low temperature $\left(30-130^{\circ} \mathrm{C}\right)$ weight loss of $17.2 \mathrm{wt} . \%$ (Calculated $=18.0 \mathrm{wt} . \%$ ), most likely due to the loss of coordinated and lattice water molecules present in this metal complex, afterwards a second thermal event presents a weight loss of $31.70 \mathrm{wt}$. \% occurring around $250-360^{\circ} \mathrm{C}$. This corresponds to the decomposition of Cromolyn-Zn. Subsequently, a higher temperature $\left(360-700^{\circ} \mathrm{C}\right)$ weight loss of 15.33 wt. \% occurred, which was attributed to the degradation of zinc/zinc oxide. 


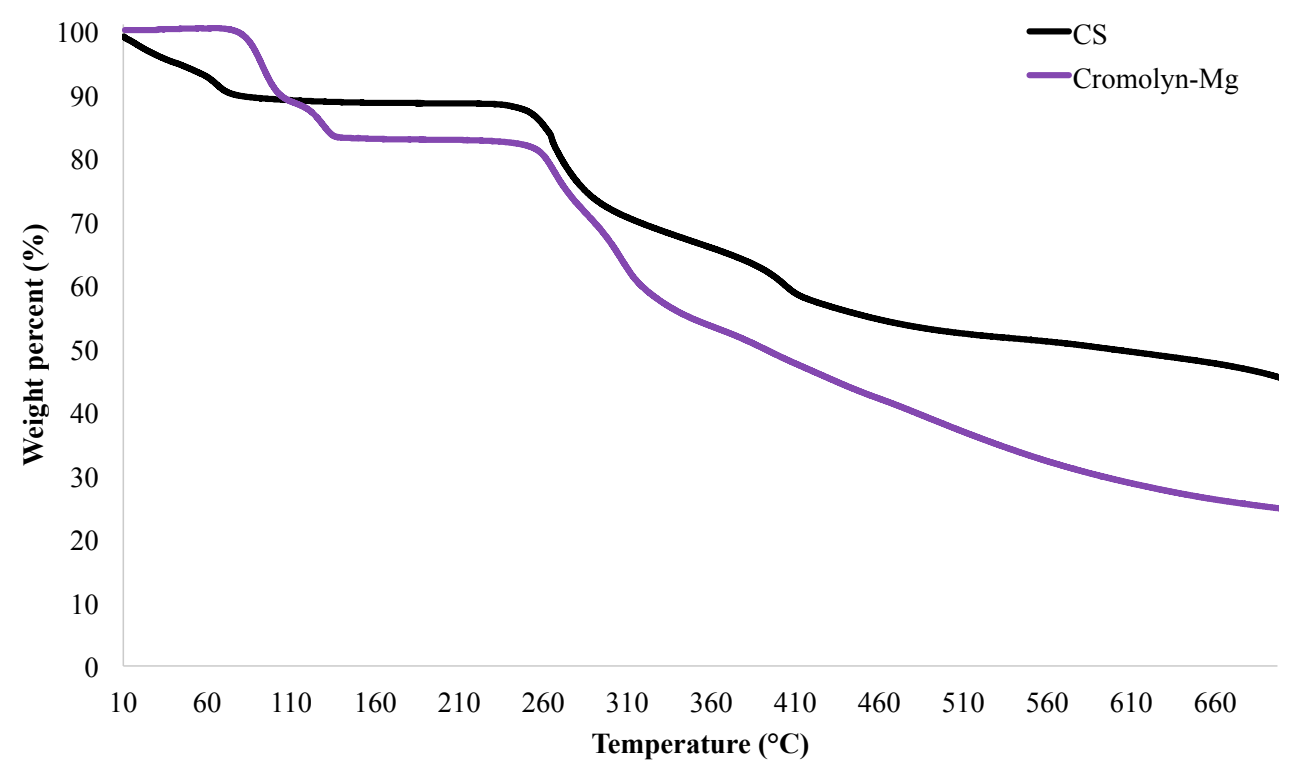

Figure S7.2. The TGA thermograph of Cromolyn-Mg starts with a low temperature $\left(30-130^{\circ} \mathrm{C}\right)$ loss of $17.0 \mathrm{wt}$. \% (Calculated $=18.0 \mathrm{wt} . \%$ ), that occurs as a consequence of the loss of the coordinated and lattice water molecules present in this metal complex. Afterwards a second thermal event $\left(230-360^{\circ} \mathrm{C}\right)$ is shown with a weight loss of 29.62 wt. \%. This degradation is attributed to the decomposition of Cromolyn-Mg. Subsequently, between $360-700^{\circ} \mathrm{C}$ a weight loss of $28.70 \mathrm{wt}$. \% occurred due to the degradation of magnesium/magnesium oxide. 


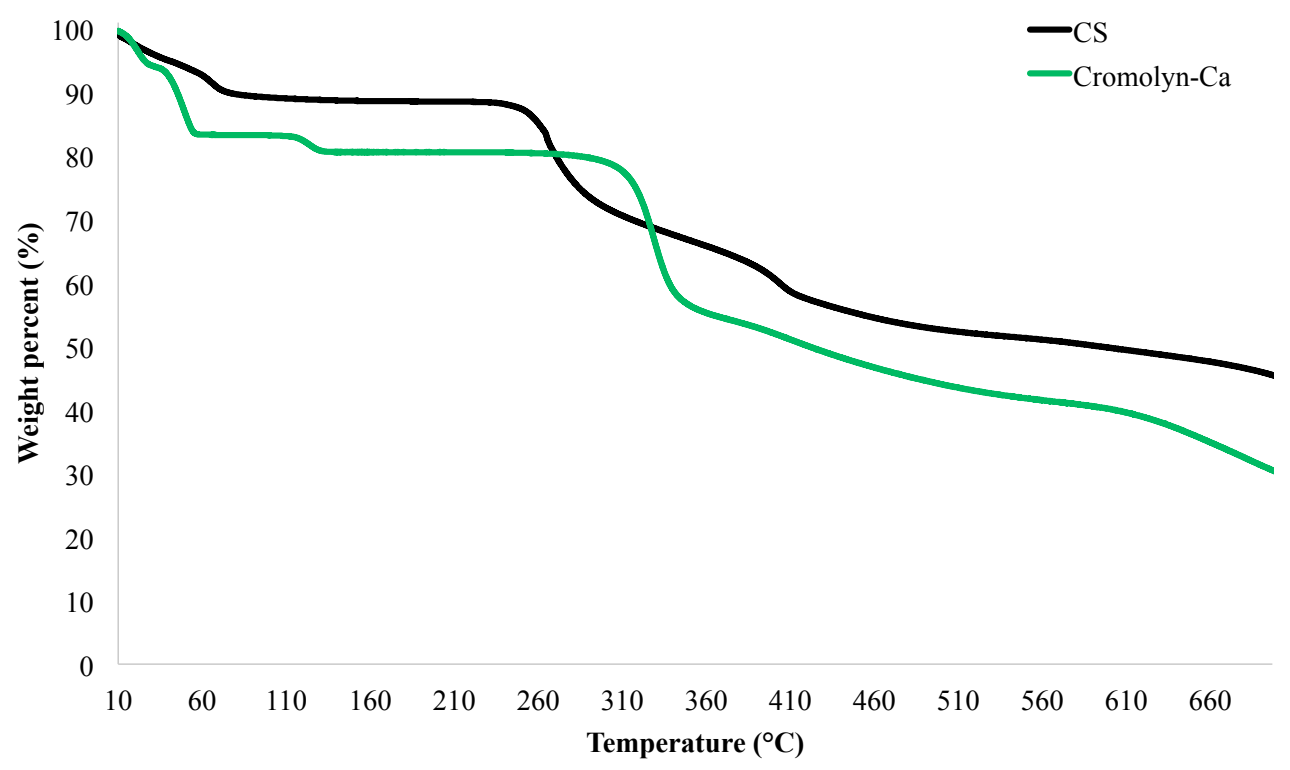

Figure S7.3. The TGA thermograph of Cromolyn-Ca starts with a low temperature $\left(30-130^{\circ} \mathrm{C}\right)$ weight loss of 19.4 wt. \% (Calculated $=19.9$ wt. \%). This is most likely a consequence of the loss of coordinated and lattice water molecules present in this metal complex. Subsequently, a second thermal event occurs at a higher temperature range $\left(250-360^{\circ} \mathrm{C}\right)$, which accounts for a weight loss of loss of $29.78 \mathrm{wt}$. \%. The second thermal event is attributed to the decomposition of Cromolyn-Ca. A third degradation with a weight loss of 34.25 wt. \% occurs between 360 and $700^{\circ} \mathrm{C}$ and is attributed to the degradation of calcium/calcium oxide.

\section{Scanning Electron Microscope Coupled with Energy Dispersive Spectroscopy}

Figures S8.1.1-S8.1.3 represent scanning electron micrographs of Cromolyn-Zn, Cromolyn-Mg, and Cromolyn-Ca showing clusters and single crystals. Figures S8.2.1-S8.2.3 depict the energy dispersive spectra for the synthesized Cromolyn-Zn, Cromolyn-Mg, and Cromolyn-Ca. 


\subsection{Scanning Electron Micrographs}

\section{Cromolyn-Zn}
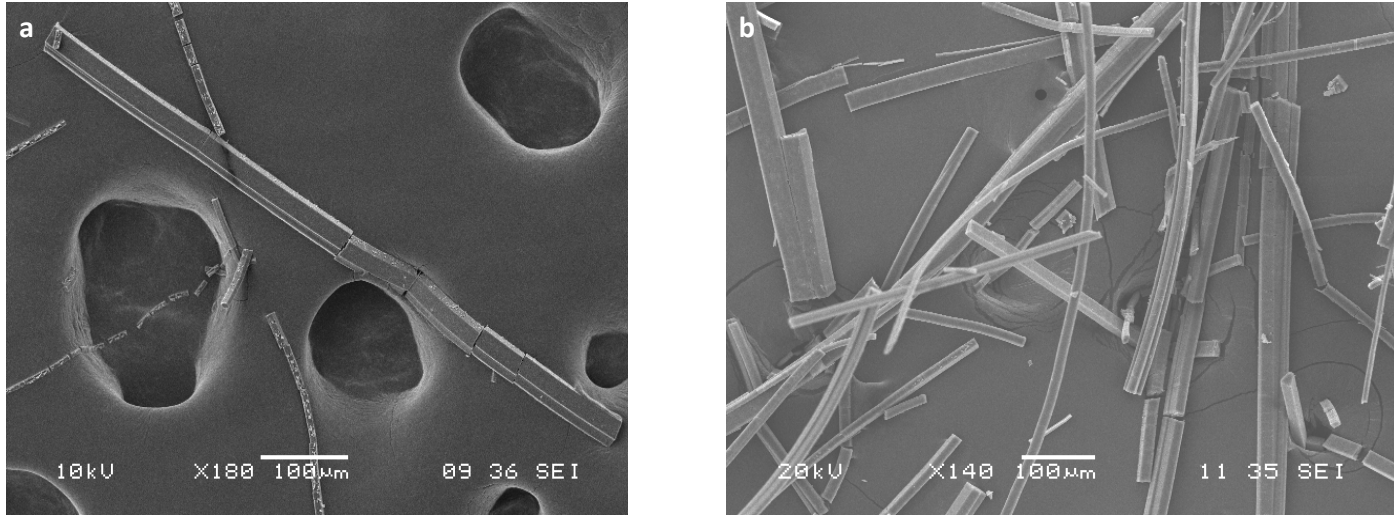

Figure S8.1.1. Scanning electron micrographs of (a) Cromolyn-Zn single crystal at a 180x magnification, and (b) crystals of Cromolyn-Zn at a 140x magnification.

\section{Cromolyn-Mg}
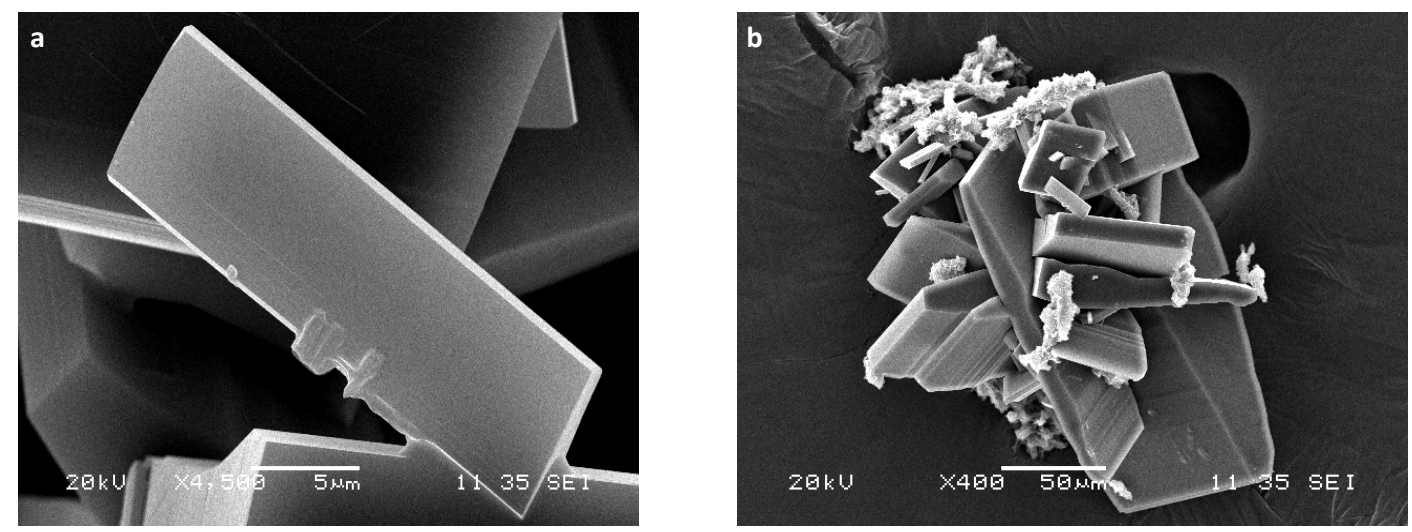

Figure S8.1.2. Scanning electron micrographs of (a) Cromolyn-Mg single crystal at a 4,500x magnification, and (b) crystals of Cromolyn-Mg at a 400x magnification. 
Cromolyn-Ca
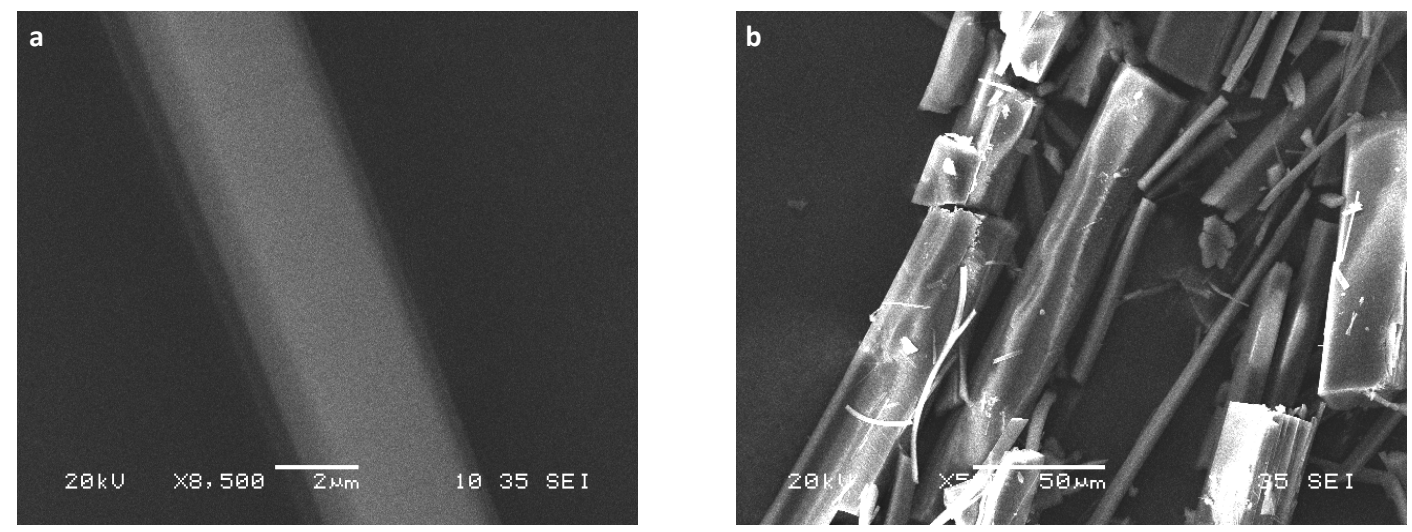

Figure S8.1.3. Scanning electron micrographs of (a) Cromolyn-Ca single crystal at a 8,500x magnification, and (b) crystals of Cromolyn-Ca at a 500x magnification.

\subsection{Energy Dispersive Spectra}

Cromolyn-Zn

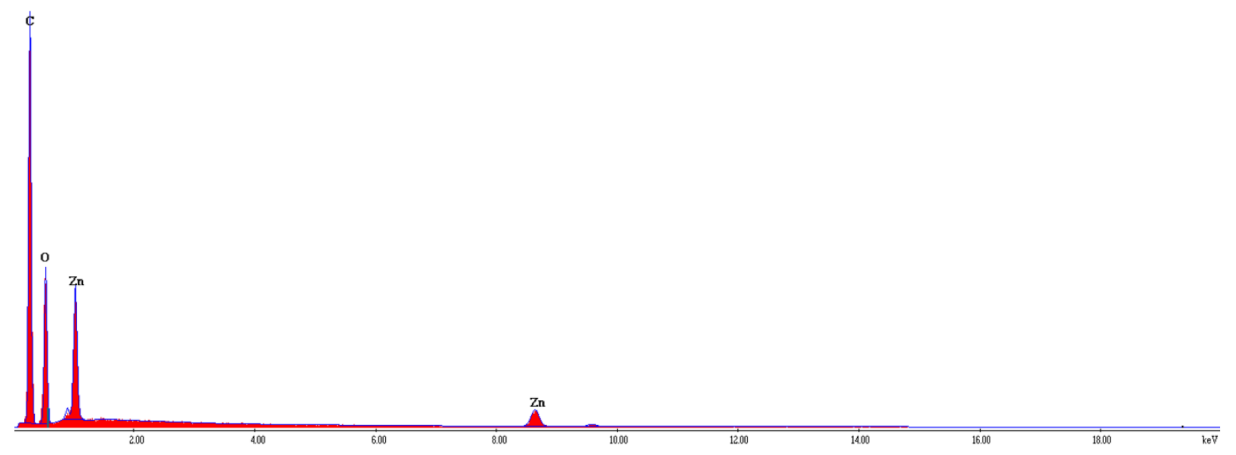

Figure S8.2.1. Energy dispersive spectra of Cromolyn-Zn displaying the presence of atoms (carbon and oxygen) present in cromolyn and the metal (zinc). 
Cromolyn-Mg

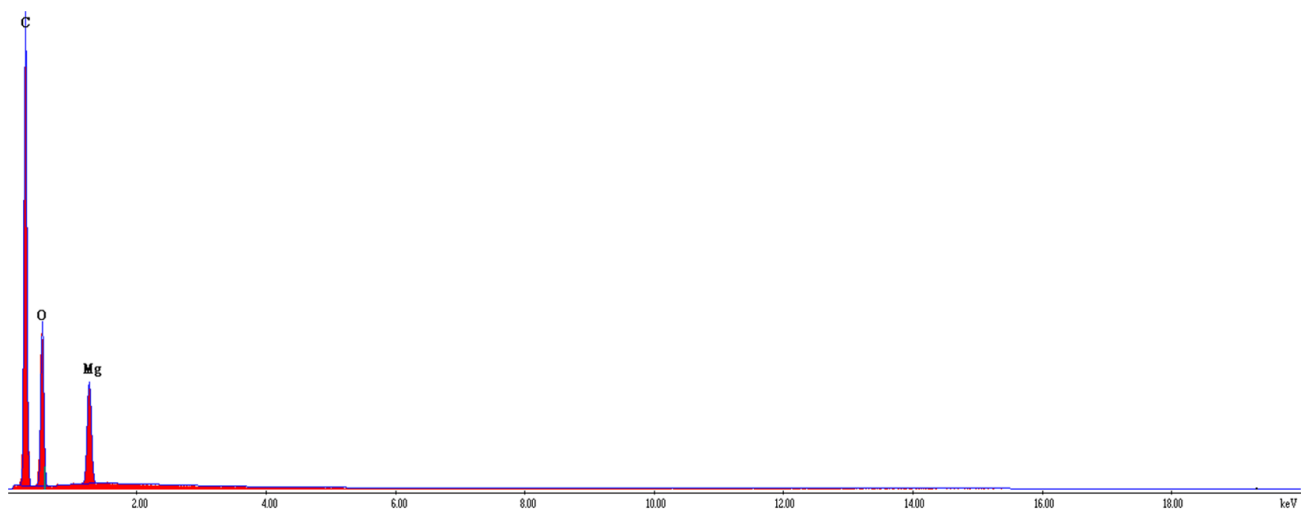

Figure S8.2.2. Energy dispersive spectra of Cromolyn-Mg displaying the presence of atoms (carbon and oxygen) present in cromolyn and the metal (magnesium).

\section{Cromolyn-Ca}

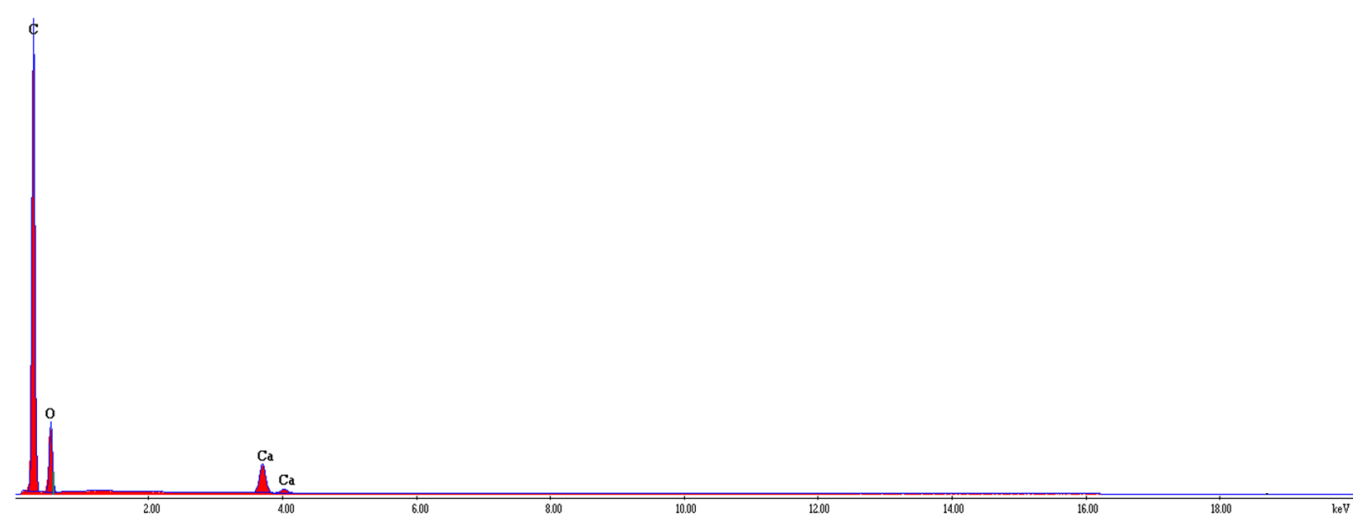

Figure S8.2.3. Energy dispersive spectra of Cromolyn-Ca displaying the presence of atoms (carbon and oxygen) present in cromolyn and the metal (calcium). 


\section{Dissolution Profiles}

Stock Solution: A standard stock solution of CS was prepared by dissolving $10 \mathrm{mg}$ in a $100 \mathrm{~mL}$ $(0.1 \mathrm{mg} / \mathrm{mL})$ volumetric flask and completing to volume with PBS. Dilute solutions were obtained by appropriate dilution of this stock solution.

Calibration Curve: Accurately measured aliquots of the stock solution were transferred into a series of volumetric flasks and resulted in standard solutions with a concentration range between 0.004 and $0.02 \mathrm{mg} / \mathrm{mL}$. PBS was used as the solvent. The absorbance of CS was measured at maximum absorption wavelength $\left(\lambda_{\max }\right)$ of $237 \mathrm{~nm}$ against a solvent blank (PBS). Figure S9.1 displays the absorbance spectra of CS, and Figure S9.2 presents the calibration curve of CS in PBS.

Dissolution profile: Dissolution profiles were recorded for CS, Cromolyn-Zn, Cromolyn-Mg, and Cromolyn-Ca. Dissolution assays were performed for CS-Zn and CS-Ca in $150 \mathrm{~mL}$ of PBS buffer ( $\mathrm{pH}=7.40)$, controlling the temperature at $37^{\circ} \mathrm{C}$ and stirring at $150 \mathrm{rpm}$. About $30 \mathrm{mg}$ of pulverized Cromolyn-Zn and Cromolyn-Ca was used for the dissolution measurements. In the case of Cromolyn-Mg, $\sim 10 \mathrm{mg}$ of the pulverized solid were employed for the dissolution profile measurement and the total volume of PBS in the dissolution vessel was decreased to $100 \mathrm{~mL}$.

The pulverized powder of each CS metal complex was added to the respective volume of PBS at the beginning of the dissolution while the temperature $\left(37^{\circ} \mathrm{C}\right)$ and stirring was constant (150 rpm). Aliquots of $1 \mathrm{~mL}$ were collected at $0,1,2,4,6,8,12,19.5$ and $24 \mathrm{hrs}$. for Cromolyn$\mathrm{Zn}$, for Cromolyn-Mg aliquots were collected at 0, 1, 3, 6, 19.5, and 24 hrs., and for Cromolyn$\mathrm{Ca}$ aliquots were collected at $0,1,3,6,18$, and $24 \mathrm{hrs}$. The aliquots were placed in $10 \mathrm{~mL}$ volumetric flasks and completed to volume with PBS. The absorbance of CS was measured at $237 \mathrm{~nm}$ against the solvent blank. The comparison of the dissolution profiles of each metal complex against CS is displayed on Figures S9.3-S9.5. Absorbance measurements were performed on an Agilent Technologies Cary Series UV-Vis Spectrophotometer, Cary 100 UVVis; using the UV Cary Scan software version v.20.0.470. All measurements were performed with a 400-200 nm scan. 


\section{Calibration Curve}

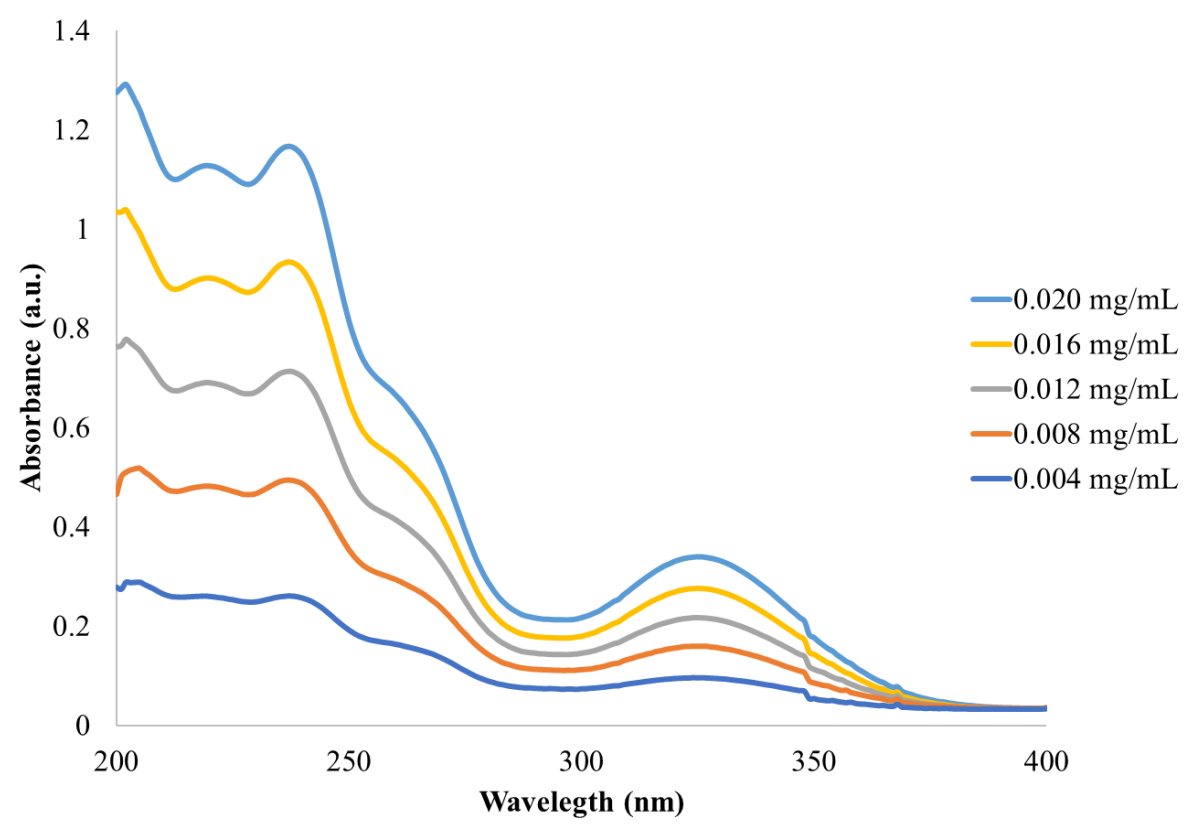

Figure S9.1. Absorbance spectra of CS presenting a maximum absorption wavelength $\left(\lambda_{\max }\right)$ at $237 \mathrm{~nm}$ in PBS. At $\lambda=237 \mathrm{~nm}$, the metal complexes do not absorb, and thus, only the excitation spectrum of CS would be recorded.

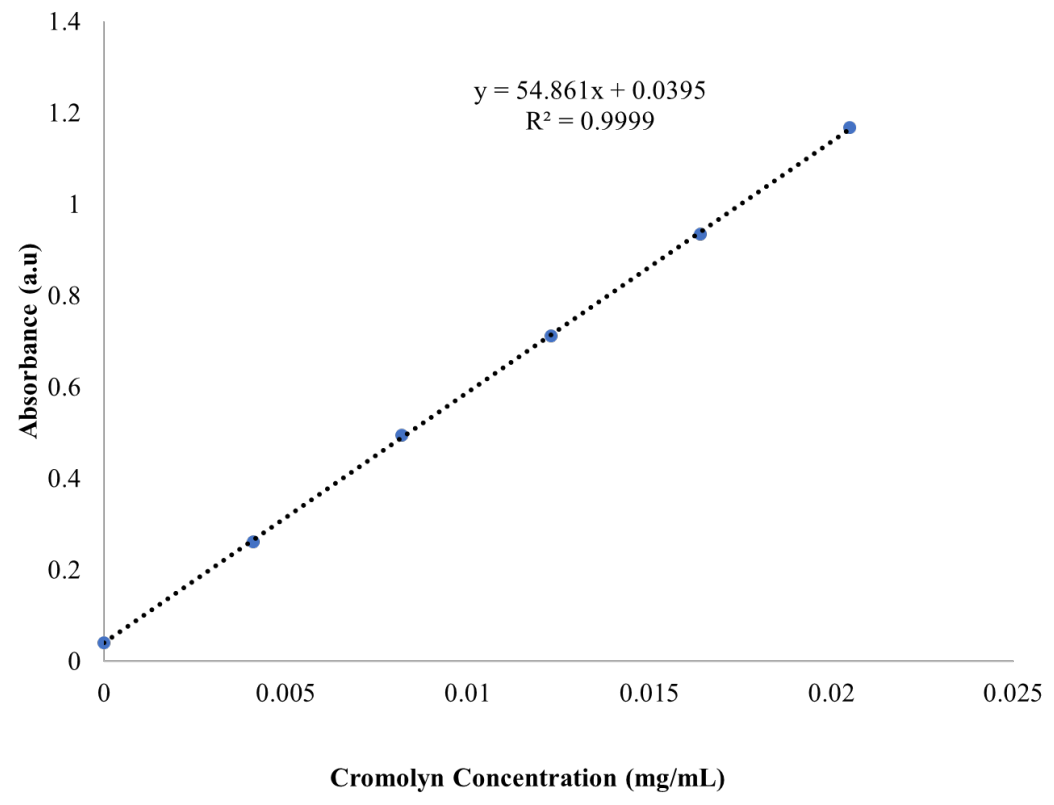

Figure S9.2. Calibration curve of CS in PBS (0.004 - $0.02 \mathrm{mg} / \mathrm{mL})$. 


\section{Dissolution profiles}

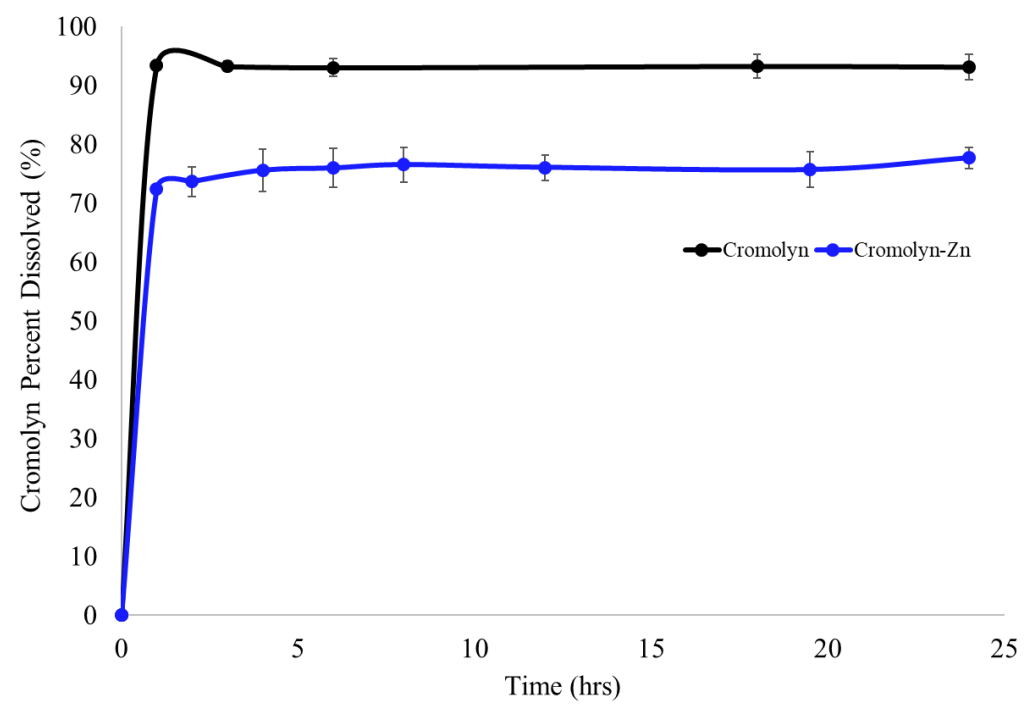

Figure S9.3. Dissolution profile (24 hrs.) in PBS of CS (black) and Cromolyn-Zn (blue).

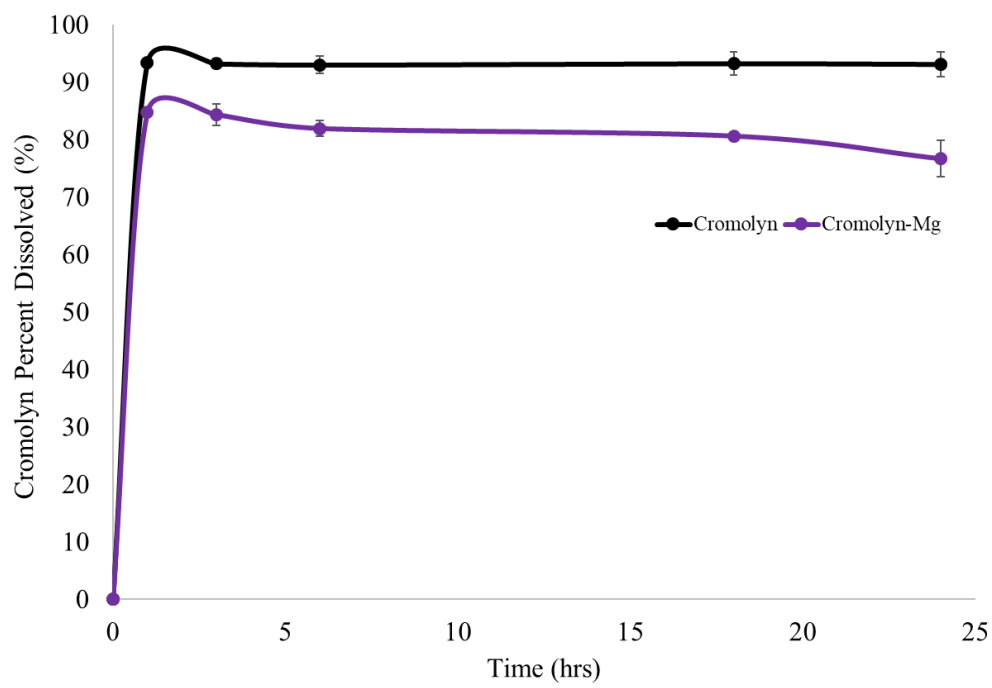

Figure S9.4. Dissolution profile (24 hrs.) in PBS of CS (black) and Cromolyn-Mg (purple). 


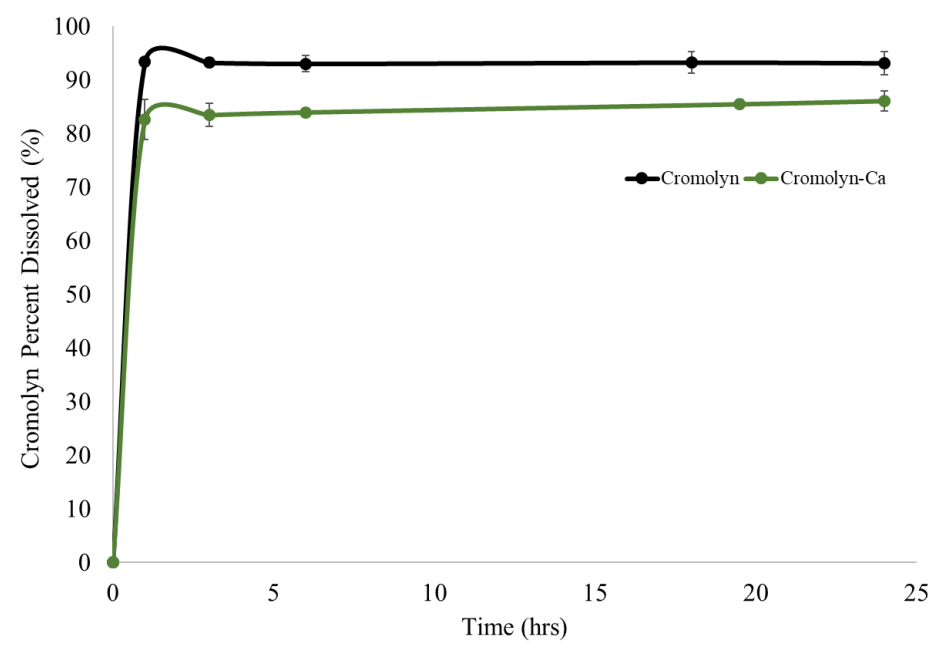

Figure S9.5. Dissolution profile (24 hrs.) in PBS of CS (black) and Cromolyn-Ca (green).

\section{References}

(1) Chen, L. R.; Young Jr., V. G.; Lechuga-Ballesteros, D.; Grant, D. J. W. Solid-State Behavior of Cromolyn Sodium Hydrates. J. Pharm. Sci. 1999, 88 (11), 1191-1200. https://doi.org/10.1021/js9900710.

(2) Ding, X.; Stringfellow, T. C.; Robinson, J. R. Self-Association of Cromolyn Sodium in Aqueous Solution Characterized by Nuclear Magnetic Resonance Spectroscopy. J. Pharm. Sci. 2004, 93 (5), 1351-1358. https://doi.org/10.1002/jps.20034.

(3) Attwood, D.; Agarwal, S. P. Self-Association of Disodium Cromoglycate in Dilute Aqueous Solution. Int. J. Pharm. 1984, 22 (1), 25-30. https://doi.org/10.1016/03785173(84)90042-5. 